\title{
Colorectal epithelial neoplasm associated with gut-associated lymphoid tissue
}

\author{
Yo Han Jeon, Ji Hyun Ahn, Hee Kyung Chang \\ Department of Pathology, Kosin University College of Medicine, Busan, Korea
}

\begin{abstract}
Background: Colorectal epithelial neoplasm extending into the submucosal gut-associated lymphoid tissue (GALT) can cause difficulties in the differential diagnosis. Regarding GALT-associated epithelial neoplasms, a few studies favor the term "GALT carcinoma" while other studies have mentioned the term "GALT-associated pseudoinvasion/epithelial misplacement (PEM)". Methods: The clinicopathologic characteristics of 11 cases of colorectal epithelial neoplasm associated with submucosal GALT diagnosed via endoscopic submucosal dissection were studied. Results: Eight cases (72.7\%) were in males. The median age was 59 years, and age ranged from 53 to 73 . All cases had a submucosal tumor component more compatible with GALT-associated PEM. Eight cases (72.7\%) were located in the right colon. Ten cases (90.9\%) had a non-protruding endoscopic appearance. Nine cases (81.8\%) showed continuity between the submucosal and surface adenomatous components. Nine cases showed (81.8\%) focal defects or discontinuation of the muscularis mucosae adjacent to the submucosal GALT. No case showed hemosiderin deposits in the submucosa or desmoplastic reaction. No case showed single tumor cells or small clusters of tumor cells in the submucosal GALT. Seven cases (63.6\%) showed goblet cells in the submucosa. No cases showed oncocytic columnar cells lining submucosal glands. Conclusions: Our experience suggests that pathologists should be aware of the differential diagnosis of GALT-associated submucosal extension by colorectal adenomatous neoplasm. Further studies are needed to validate classification of GALT-associated epithelial neoplasms.
\end{abstract}

Key Words: Humans; Colorectal neoplasms; Lymphoid tissue; Adenomatous polyps

Received: September 2, 2019 Revised: November 4, 2019 Accepted: November 5, 2019

Corresponding Author: Hee Kyung Chang, MD, Department of Pathology, Kosin University College of Medicine, 262 Gamcheon-ro, Seo-gu, Busan 49267, Korea Tel: 82-51-990-6323, Fax: 82-51-241-7420, E-mail: changhkg@ns.kosinmed.or.kr

The gut-associated lymphoid tissue (GALT) system consists of scattered lymphoid cells in the lamina propria and organized lymphoid aggregates or follicles in the mucosa or submucosa [1-5]. GALT serves as part of both the immune system and the mucosal repair system of the gastrointestinal tract $[1,6]$. The association between GALT and various colorectal pathologic conditions-from inflammatory bowel disease to benign and malignant neoplasms-has been discussed [7-10]. Colorectal epithelial neoplasms located in the submucosa and surrounded by GALT may be encountered in daily practice and occasionally cause difficulties in differential diagnosis. The term "GALT carcinoma" has been suggested as a distinct malignancy arising from the GALT mucosal domain and representing the "third pathway of colorectal carcinogenesis". However, GALT carcinoma is not recognized as a distinct histologic subtype in current colorectal cancer classifications [2,11-28]. A few studies have suggested
GALT-associated pseudoinvasion/epithelial misplacement (PEM) as a consideration in the differential diagnosis of GALT-associated tumors [11,12]. However, there are few studies in the Korean literature clarifying the pathologic nature of colorectal epithelial neoplasms located in submucosal GALT. Herein, we investigated the clinicopathologic characteristics of colorectal epithelial neoplasms associated with submucosal GALT.

\section{MATERIALS AND METHODS}

\section{Case selection}

Eleven cases of colorectal epithelial neoplasm, involving submucosal GALT, identified after endoscopic submucosal dissection, were studied from the pathologic archives of Kosin University Gospel Hospital (Busan, Korea), over a 7-year period from January 2012 to December 2018. 


\section{Clinicopathologic analysis}

The following clinicopathologic features were extracted from the medical record: age, sex, location, endoscopic appearance. The location of the neoplasm was classified according to the International Classification of Diseases for Oncology classification [29] and was categorized into either right-sided colon (including cecum, ascending colon, hepatic flexure and transverse colon) or left-sided colon (including splenic flexure, descending colon, sigmoid colon, and rectum) [30].

The endoscopic appearance of the neoplasms were classified according to the Paris classification [31-35]. With regard to the distinction between sessile protruding type (0-Is) and slightly elevated non-protruding type (0-IIa), a more practical definition was applied instead of the definition using the cut-off value of $2.5 \mathrm{~mm}$ or twice the thickness of surrounding normal colorectal mucosa: a superficial neoplastic lesion with the height more than one-third of the diameter was classified into protruding type $[31,35]$.

\section{Histopathologic evaluation}

For each case, hematoxylin and eosin-stained slides were reviewed, and the pathologic diagnoses were reclassified by three pathologists (Y.H.J., J.H.A., and H.K.C.).

Submucosal GALT was defined as lymphoid aggregates or follicles located below the muscularis mucosae $[3,6,8]$. A colorectal epithelial neoplasm located in the submucosal GALT was defined as a colorectal epithelial neoplasm involving the submucosal GALT.

Conventional adenomas were classified into three subtypes based on the amount of villous component: tubular (villous component less than 25\%), tubulovillous (villous component $25 \%$ to $75 \%$ ), and villous adenoma (villous component more than $75 \%$ ) [36].

Dysplasia was graded into either low-grade or high-grade. Non-complex architecture with elongated and pseudostratified nuclei was graded as low-grade dysplasia [36]. Complex architecture (markedly irregular, crowded, cribriform, or fused glands) with accompanying cytologic features (loss of nuclear polarity, pleomorphic nuclei) was graded as high-grade dysplasia [36]. Dysplastic glands without complex architecture were not considered high-grade dysplasia.

The following histologic features for PEM were evaluated: grade of dysplasia in submucosal glands, continuity of submucosal glands with surface adenomatous component, focal defect of muscularis mucosae adjacent to submucosal GALT, hemosiderin deposits in submucosa, contour of submucosal GALT, cystic dila- tion of submucosal glands, and admixture of submucosal glands with normal colonic epithelium [11,12,37-45].

The following histologic features suggesting frank invasion were evaluated: desmoplasia, single or small clusters of tumor cells, and lymphovascular invasion [46].

The following histologic features characteristic of GALT carcinoma were evaluated: oncocytic cytoplasm of submucosal glands and depletion of goblet cells in submucosal glands [13-28,47].

The size of the entire tumor was measured to the first digit after the decimal point $(\mathrm{cm})$. The diameter of the largest isolated submucosal lymphoid aggregate or follicle involved by the neoplasm was measured to the second digit after the decimal point $(\mathrm{cm})$.

\section{Immunohistochemical study}

To evaluate the muscularis mucosae, immunohistochemical staining for desmin was performed. Paraffin-embedded tissue sections with $5 \mu \mathrm{m}$ thickness were deparaffinized in xylene and rehydrated by a graded series of ethyl alcohol concentrations. Heat-induced antigen retrieval was carried out in citrate buffer ( $\mathrm{pH}$ 6.0). Sections were incubated with the primary antibody for desmin (1:200, D33, DAKO, Glostrup, UK) in a Bond-MAX automated immunostainer (Leica, Wetzlar, Germany) according to the manufacturer's protocols. Counterstaining with Mayer's hematoxylin was performed.

\section{Statistical analysis}

Clinical features including location (number 1 assigned for right-sided, number 2 assigned for left-sided), sex (number 1 assigned for male, number 2 assigned for female), and endoscopic appearance (number 1 assigned for protruding, number 2 assigned for non-protruding) were analyzed by single sample $t$ test with a test value of 1.5 .

The relationship between "the grade of dysplasia in the submucosal GALT" and pathologic features (including pathologic size of the entire lesion and largest diameter of isolated submucosal GALT involved) were analyzed by Mann-Whitney test.

The relationship between "the grade of dysplasia in the submucosal GALT" and the remaining clinicopathologic features (including those for PEM, frank invasion, and GALT carcinoma) were analyzed by chi-square test and Fisher exact probability test.

A p-value less than .05 was considered statistically significant. All statistics were analyzed using SPSS ver. 25.0 (IBM Corp., Armonk, NY, USA). 


\section{Ethics statement}

This retrospective study was approved by the Institutional Review Board of Kosin University Gospel Hospital with a waiver of informed consent (IRB No. 2019-08-009) and performed in accordance with the principles of the Declaration of Helsinki [48].

\section{RESULTS}

\section{Clinical characteristics}

In the 11 cases of colorectal neoplasms involving submucosal GALT, the median age was 59 years (ranging from 53 to 73 years). Eight cases (72.7\%) occurred in males. Only one case (case 3) showed protruding or "dome-shaped" endoscopic appearance. The other 10 cases showed non-protruding endoscopic appearance. Eight cases $(72.7 \%)$ were in the right-sided colon. Clinical characteristics of the 11 cases were summarized in Tables 1 and 2 .
With median follow-up duration of 17 months (ranging from 5 to 61 months), no recurrence was identified (data not shown in Tables 1 and 2).

\section{Pathologic features}

The pathologic diagnoses of the 11 cases included tubular adenoma with low grade dysplasia $(n=3,27.3 \%)$ and tubular adenoma with high-grade dysplasia $(n=8,72.7 \%)$. Three cases $(27.3 \%)$ showed high-grade dysplasia in submucosal glands; the other eight cases $(72.7 \%)$ showed low-grade dysplasia in submucosal glands. Nine cases $(81.8 \%)$ showed continuity between submucosal and surface adenomatous components. Nine cases showed $(81.8 \%)$ a focal defect or discontinuation of the muscularis mucosae adjacent to submucosal GALT (Fig. 1). No case showed hemosiderin deposition in the submucosa. Ten cases (90.9\%) had rounded or lobular architecture of submucosal GALT involved in the glands; in the other case without rounded

Table 1. Clinicopathologic characteristics of colorectal neoplasm associated with submucosal GALT

\begin{tabular}{|c|c|c|c|c|c|c|c|c|c|c|c|}
\hline & Case 1 & Case 2 & Case 3 & Case 4 & Case 5 & Case 6 & Case 7 & Case 8 & Case 9 & Case 10 & Case 11 \\
\hline Age (yr) & 56 & 58 & 66 & 53 & 70 & 71 & 55 & 73 & 73 & 59 & 54 \\
\hline Sex & $\mathrm{F}$ & M & F & M & M & M & M & $\mathrm{F}$ & $M$ & M & M \\
\hline Location & Rectum & Ascending & Sigmoid & Ascending & Transverse & Ascending & Rectum & Transverse & Transverse & $\mathrm{HF}$ & Transverse \\
\hline Endoscopic appearance ${ }^{a}$ & $0-11 a+$ Is & 0-Ila & 0 -Is & 0-Ila & 0-Ila & 0-\|la & $0-\| c$ & 0-Ila & $0-11 a+$ Is & 0-lla & 0-Ila \\
\hline Pathologic diagnosis & $\begin{array}{l}\text { TA w/ } \\
\text { HGD }\end{array}$ & $\begin{array}{l}\text { TA w/ } \\
\text { HGD }\end{array}$ & $\begin{array}{l}\text { TA w/ } \\
\text { HGD }\end{array}$ & $\begin{array}{l}\text { TA w/ } \\
\text { HGD }\end{array}$ & $\begin{array}{l}\text { TA w/ } \\
\text { HGD }\end{array}$ & $\begin{array}{l}\text { TA w/ } \\
\text { LGD }\end{array}$ & $\begin{array}{l}\text { TA w/ } \\
\text { HGD }\end{array}$ & $\begin{array}{l}\text { TA w/ } \\
\text { HGD }\end{array}$ & $\begin{array}{l}\text { TA w/ } \\
\text { HGD }\end{array}$ & TA w/ LGD & TA w/ LGD \\
\hline Dysplasia in the SM GALT & LGD & LGD & HGD & LGD & LGD & LGD & LGD & HGD & HGD & LGD & LGD \\
\hline $\begin{array}{l}\text { Continuity of SM glands } \\
\text { with surface adenomatous } \\
\text { component }\end{array}$ & + & - & + & + & + & + & - & + & + & + & + \\
\hline $\begin{array}{l}\text { Focal defect of MM adjacent } \\
\text { to the SM GALT }\end{array}$ & + & - & + & + & + & + & - & + & + & + & - \\
\hline $\begin{array}{l}\text { Hemosiderin deposit in } \\
\text { the SM }\end{array}$ & - & - & - & - & - & - & - & - & - & - & - \\
\hline $\begin{array}{l}\text { Rounded contour of involved } \\
\text { SM GALT }\end{array}$ & + & + & - & + & + & + & + & + & + & + & + \\
\hline Cystic dilatation of SM glands & + & - & + & - & - & - & - & - & - & - & + \\
\hline $\begin{array}{l}\text { Admixture of SM glands with } \\
\text { normal colonic epithelium }\end{array}$ & - & - & - & - & - & - & - & - & - & - & + \\
\hline Desmoplasia & - & - & - & - & - & - & - & - & - & - & - \\
\hline $\begin{array}{l}\text { Single or small clusters of } \\
\text { tumor cells in the SM GALT }\end{array}$ & - & - & - & - & - & - & - & - & - & - & - \\
\hline Lymphovascular invasion & - & - & - & - & - & - & - & - & - & - & - \\
\hline $\begin{array}{l}\text { Oncocytic cytoplasm of the } \\
\text { SM glands }\end{array}$ & - & - & - & - & - & - & - & - & - & - & - \\
\hline Goblet cells in the SM glands & + & + & - & - & + & - & + & + & + & - & + \\
\hline $\begin{array}{l}\text { Histologic size of the entire } \\
\text { tumor }(\mathrm{cm})\end{array}$ & 1.7 & 1.4 & 1.5 & 2.2 & 1.2 & 2.1 & 1.5 & 1.8 & 1.2 & 2.7 & 1.8 \\
\hline $\begin{array}{l}\text { The largest diameter of } \\
\text { isolated SM GALT }(\mathrm{cm})\end{array}$ & 0.14 & 0.13 & 0.33 & 0.17 & 0.14 & 0.21 & 0.29 & 0.12 & 0.23 & 0.14 & 0.19 \\
\hline
\end{tabular}

GALT, gut-associated lymphoid tissue; F, female; M, male; TA, tubular adenoma; w/, with; HGD, high-grade dysplasia; LGD, low-grade dysplasia; SM, submucosa or submucosal; 0-Is, protruding and sessile type; 0-lla, flat elevated type; 0-Ilc, slightly depressed type; +, present; -, absent; \pm , inconspicuous. aEndoscopic appearance was classified according to the Paris classification. 0-lla+ls corresponds to "nodular mixed type of the granular laterally spreading tumor." 0-lla corresponds to either "homogeneous type of granular laterally spreading tumor" or "flat elevated type of non-granular laterally spreading tumor." 
Table 2. Summary of clinicopathologic characteristics of colorectal neoplasm associated with submucosal GALT and relationship with grade of dysplasia in submucosa

\begin{tabular}{|c|c|c|c|c|}
\hline & Total $(n=11)$ & HGD in the SM $(n=3)$ & LGD in the SM $(n=8)$ & $\mathrm{p}$-value \\
\hline Age (yr) & $59(53-73)$ & $73(66-73)$ & $57(53-71)$ & \\
\hline Sex & & & & .138 \\
\hline Male & $8(72.7)$ & $1(33.3)$ & $7(87.5)$ & \\
\hline Female & $3(27.3)$ & $2(66.7)$ & $1(12.5)$ & \\
\hline Endoscopic appearance ${ }^{a}$ & & & & .001 \\
\hline Protruding & $1(9.1)$ & $1(33.3)$ & 0 & \\
\hline Non-protruding & $10(90.9)$ & $2(66.7)$ & $8(100)$ & \\
\hline Location & & & & .138 \\
\hline Right-sided & $8(72.7)$ & $2(66.7)$ & $6(75.0)$ & \\
\hline Left-sided & $3(27.3)$ & $1(33.3)$ & $2(25.0)$ & \\
\hline Pathologic diagnosis of entire ESD specimen & & & & .491 \\
\hline HGD & $8(72.7)$ & $3(100)$ & $5(62.5)$ & \\
\hline LGD & $3(27.3)$ & 0 & $3(37.5)$ & \\
\hline Continuity of SM glands with surface adenomatous component & & & & $>.99$ \\
\hline Continued & $9(81.8)$ & $3(100.0)$ & $6(75.0)$ & \\
\hline Discontinued & $2(18.2)$ & $0(0.0)$ & $2(25.0)$ & \\
\hline Focal defect of MM adjacent to SM GALT & & & & $>.99$ \\
\hline Continued & $2(18.2)$ & 0 & $2(25.0)$ & \\
\hline Discontinued & $9(81.8)$ & $3(100)$ & $6(75.0)$ & \\
\hline Hemosiderin deposit in the SM & & & & - \\
\hline Present & 0 & 0 & 0 & \\
\hline Absent & $11(100)$ & $3(100)$ & $8(100)$ & \\
\hline Contour of involved SM GALT & & & & .273 \\
\hline Rounded & $10(90.9)$ & $2(66.7)$ & $8(100)$ & \\
\hline Irregular & $1(9.1)$ & $1(33.3)$ & 0 & \\
\hline Cystic dilatation of SM glands & & & & $>.99$ \\
\hline Present & $3(27.3)$ & $1(33.3)$ & $2(25.0)$ & \\
\hline Absent & $8(72.7)$ & $2(66.7)$ & $6(75.0)$ & \\
\hline Admixture of SM glands with normal colonic epithelium & & & & $>.99$ \\
\hline Present & $1(9.1)$ & 0 & $1(12.5)$ & \\
\hline Absent & $10(90.9)$ & $3(100)$ & $7(87.5)$ & \\
\hline Desmoplasia & & & & - \\
\hline Present & 0 & 0 & 0 & \\
\hline Absent & $11(100)$ & $3(100)$ & $8(100)$ & \\
\hline Single or small clusters of tumor cells in the SM GALT & & & & - \\
\hline Present & 0 & 0 & 0 & \\
\hline Absent & $11(100)$ & $3(100)$ & $8(100)$ & \\
\hline Lymphovascular invasion & & & & - \\
\hline Present & 0 & 0 & 0 & \\
\hline Absent & $11(100)$ & $3(100)$ & $8(100)$ & \\
\hline Oncocytic cytoplasm of the SM glands & & & & - \\
\hline Present & 0 & 0 & 0 & \\
\hline Absent & $11(100)$ & $3(100)$ & $8(100)$ & \\
\hline Goblet cells in the SM glands & & & & - \\
\hline Present & $7(63.6)$ & $2(66.7)$ & $5(62.5)$ & \\
\hline Absent & $4(36.4)$ & $1(33.3)$ & $3(37.5)$ & \\
\hline Pathologic size of entire lesion (cm) & $1.7(1.2-2.7)$ & $1.5(1.2-1.8)$ & $1.75(1.2-2.7)$ & \\
\hline The largest diameter of isolated SM GALT (cm) & $0.17(0.12-0.33)$ & $0.23(0.12-0.33)$ & $0.155(0.13-0.29)$ & \\
\hline
\end{tabular}

Values are presented as median (range) or number (\%).

GALT, gut-associated lymphoid tissue; HGD, high-grade dysplasia; SM, submucosa or submucosal; LGD, low-grade dysplasia; ESD, endoscopic submucosal dissection.

${ }^{a}$ Endoscopic appearance was classified according to the Paris classification. 

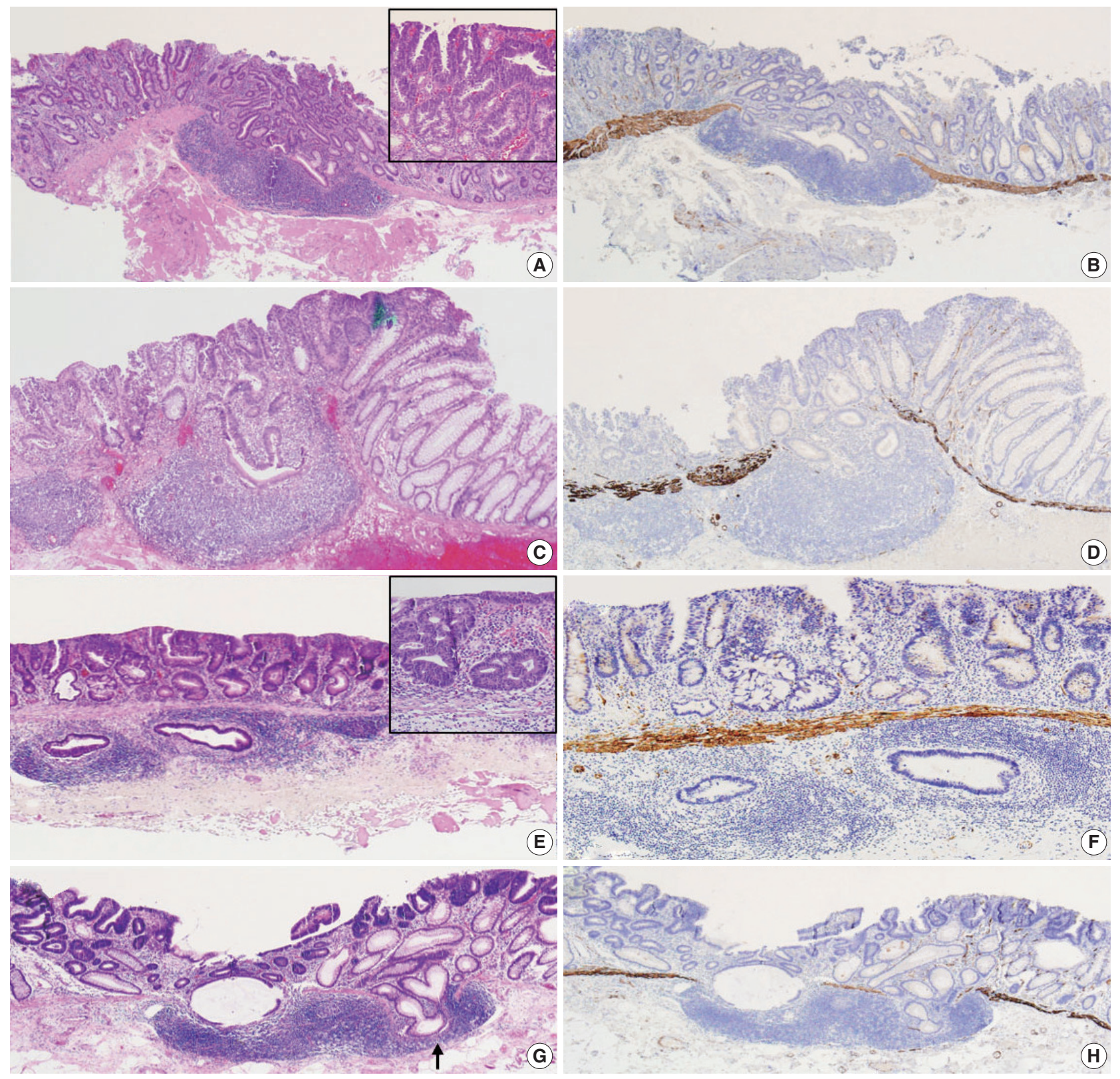

Fig. 1. Continuity of submucosal glands with surface adenomatous component and focal defect of muscularis mucosae adjacent to submucosal gut-associated lymphoid tissue (GALT). (A) Case 5. Tubular adenoma with high-grade dysplasia. Histologic continuity of submucosal glands with surface adenomatous component is seen. Submucosal glands with low-grade dysplasia show similar degree of differentiation compared with surface component. However, this neoplasm shows focal area of glands with complex architecture and corresponding high-grade cytologic features in surface mucosa elsewhere (depicted in inset). This case is more compatible with tubular adenoma with high-grade dysplasia than invasive adenocarcinoma, which usually shows less differentiated tumor cells in the deepest part of invasion. (B) Immunohistochemical $(\mathrm{HC})$ staining for desmin in case 5 shows focal defects of the muscularis mucosae with GALT-associated pseudoinvasion/epithelial misplacement (PEM). (C) Case 9. Tubular adenoma with high-grade dysplasia. Both surface adenomatous component and submucosal glands show high-grade dysplasia and histologic continuity across the muscularis mucosae. (D) $1 \mathrm{HC}$ staining for desmin in case 9 highlights discontinuous muscularis mucosae. (E) Case 2. Tubular adenoma with high-grade dysplasia. In contrast to cases 5 and 9 , no histologic continuity of submucosal glands with surface adenomatous component is seen. Inset depicts glands with high-grade dysplasia in surface mucosa. Narrow rim surrounding submucosal glands is not compatible with typical desmoplasia. Absence of single tumor cells/small clusters of tumor cells, poorly formed or back-to-back glands, solid tumor nests, or "true" desmoplasia favor diagnosis of tubular adenoma with high-grade dysplasia involving GALT (PEM) over adenocarcinoma with "true" submucosal invasion. (F) Intact muscularis mucosae with subjacent GALT of case 2 is identified with IHC staining for desmin. (G) Case 11. Tubular adenoma with low-grade dysplasia. Cystically dilated tumor glands cross through the muscularis mucosae. Note simultaneous crossing over by non-neoplastic glands (indicated by arrow). $(H) \Vdash H C$ staining for desmin in case 11. PEM via GALT is accompanied by discontinuous muscularis mucosae rather than hypertrophy of muscularis mucosae. 

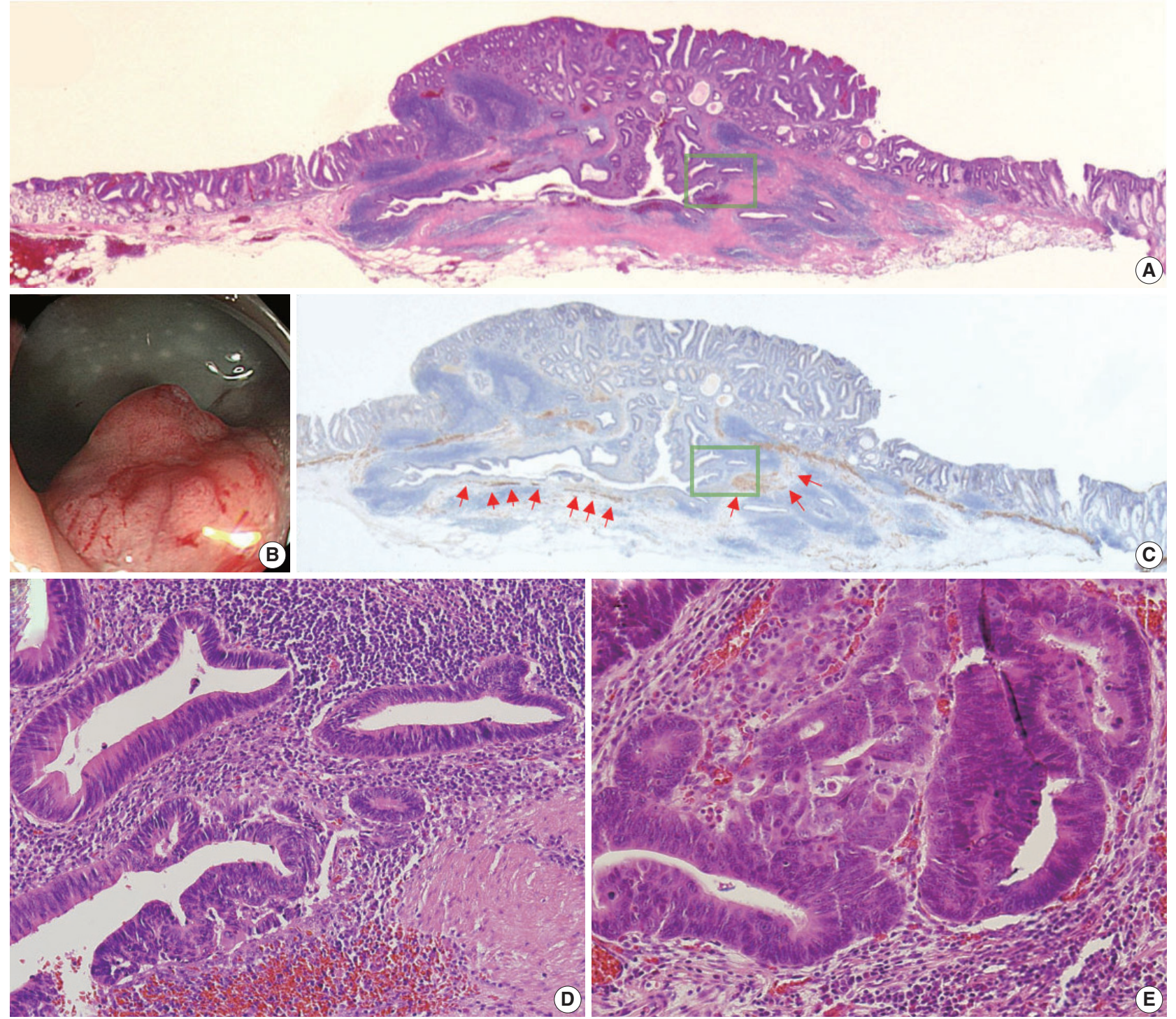

Fig. 2. Case 3. (A) Histologic continuity along with subtle rimming of muscularis mucosae in submucosa (so-called herniation pattern) favor diagnosis of tubular adenoma with high-grade dysplasia over invasive adenocarcinoma. Depth of neoplasm is more than twice the thickness of surrounding normal colorectal mucosa. (B) Endoscopic appearance of case 3. Exact measurement of neoplasm depth is not available for endoscopist. Superficial neoplastic lesion with height more than one-third of diameter is compatible with the protruding type. (C) Immunohistochemical staining for desmin in case 3. Rimming of muscularis mucosa is indicated by red arrows. (D) Glands with high-grade dysplasia are seen under imaginary line connecting adjacent muscularis mucosa beneath normal mucosa. Panel D corresponds to green boxes of panels A and C. (E) Glands of surface mucosal layer with high-grade dysplasia.

architecture (case 3), the tumor glands under the imaginary line connecting the adjacent muscularis mucosa beneath the normal mucosa were partly surrounded by submucosal GALT (Fig. 2). Three cases $(27.3 \%)$ showed cystically dilated submucosal glands. Only one case $(9.1 \%$, case 11 ) showed an admixture of non-neoplastic glands and neoplastic glands in the submucosal GALT. No case showed a desmoplastic reaction. No case showed a single tumor cell or small clusters of tumor cells in the submucosal
GALT. No case showed oncocytic cytoplasm of submucosal glands. Seven cases (63.6\%) showed goblet cells in submucosal glands. The median value of the histologic size of the entire tumor was $1.7 \mathrm{~cm}$ (range, 1.2 to $2.7 \mathrm{~cm}$ ). The median value of the largest diameter of the isolated submucosal GALT involved by epithelial neoplasm was $0.17 \mathrm{~cm}$ (range, 0.12 to $0.33 \mathrm{~cm}$ ). Pathologic characteristics of the 11 cases were summarized in Tables 1 and 2. All 11 cases of colorectal epithelial neoplasm involving submu- 
cosal GALT had a submucosal tumor component more compatible with PEM (Figs. 1, 2).

\section{Clinicopathologic characteristics of colorectal neoplasm associated with submucosal GALT in relation to grade of dysplasia}

No statistically significant difference in pathologic size of the entire lesion was identified between the two groups (high-grade dysplasia in submucosa versus low-grade dysplasia in submucosa). No statistically significant difference of the largest diameter of isolated submucosal GALT involved was identified between the two groups (high-grade dysplasia in the submucosa versus low-grade dysplasia in the submucosa) (Table 2).

No statistically significant relationship between grade of dysplasia in the submucosa (high-grade dysplasia versus low-grade dysplasia) and pathologic features (including pathologic features for PEM; continuity of submucosal glands with surface adenomatous component, focal defect of muscularis mucosae adjacent to submucosal GALT, hemosiderin deposit in the submucosa, contour of submucosal GALT, cystic dilation of submucosal glands, and admixture of submucosal glands with normal colonic epithelium; pathologic features for frank invasion; desmoplasia, single tumor cell or small clusters of tumor cells, and lymphovascular invasion; and pathologic features for GALT carcinoma; oncocytic cytoplasm of submucosal glands and depletion of goblet cells in submucosal glands) was identified (Table 2).

\section{DISCUSSION}

A consistent and close association between GALT, particularly organized lymphoid aggregates in the submucosa, and colorectal carcinogenesis, has been reported in rodent models despite scarce incidence of GALT in normal rat intestine [49-53]. However, the specific role of GALT in human colorectal carcinogenesis is not fully understood [6]. Herein, we analyzed the clinicopathologic features of eleven colorectal epithelial neoplasms involving submucosal GALT.

Eight cases $(72.7 \%)$ were in males. However, validation with a larger number of cases is required to investigate the possible sex predilection of GALT-associated neoplasms. Fu et al. [8] reported significantly higher incidence of GALT in the early colorectal neoplasms of females compared to those of males.

Eight cases $(72.7 \%)$ were located in the right-sided colon. Kealy [5] reported a more frequent incidence of GALT in the distal colon compared with the proximal colon. Langman and Rowland [4] reported similar relative abundance of GALT in the rectum, but the mean density of GALT in the normal human large intestine was approximately eight times higher than that of the previous report; the normal density of GALT in the proximal colon was not as low as that of previous data [54]. They attributed this gap to differences in the techniques used [4]. O'Leary and Sweeney [55] reported the greatest normal frequency of GALT in both the rectum and cecum, which has relatively abundant microflora [1]. Lee et al. [12] also reported the right side predilection of GALT-associated neoplasms ("tubular adenoma with pseudoinvasion" in their study).

Fu et al. [8] reported the different incidences of GALT according to different macroscopic types of colorectal neoplasm. They reported that neoplasms with depressed or flat macroscopic types showed significantly higher incidence of submucosal GALT than neoplasms with protruding macroscopic types [8]. In our study, 10 cases $(90.9 \%)$ showed non-protruding endoscopic appearances; the endoscopic appearance of the one other case (case 3) was protruding type (0-Is according to Paris classification) [31]. Several reports have emphasized the non-protruding macroscopic appearance of GALT-associated colorectal neoplasms [2,22,56].

GALT carcinoma and GALT-associated PEM share some overlapping histopathologic features, including submucosal localization, well defined round contour with expansive growth, absence of desmoplasia, cystically dilated glands, and close association with submucosal GALT $[12,13]$. Most cases of GALT carcinoma reported so far were confined to the submucosal layer; only two of 23 cases reported as GALT carcinoma showed tumor extension beyond the submucosa $[13,16,19,24]$. Some prefer to use the term "pseudoinvasion" over "epithelial misplacement," emphasizing the expansive lobular growth pattern of tumor glands located in the submucosa after herniation [41]. In fact, the unique histologic features of GALT carcinoma had once been attributed to the result of PEM from overlying conventional adenomas. Thus, the term "lymphoid-associated neoplasia in the herniated colonic epithelium" was once presented $[25,47]$. One case report author used the term "adenomatous polyp," but other researchers have used the term "GALT carcinoma" $[13,15]$.

The presence of lamina propria surrounding submucosal glandular structures strongly indicates PEM [11,12,37-45,57]. Absence of lamina propria surrounding submucosal glands along with discontinuity between surface adenomatous component and submucosal glands has been presented as a distinct feature of GALT carcinoma $[13,18]$. However, as normal lamina propria is occasionally occupied by GALT, a rim of lamina propria surrounding the submucosal glands can be obscured by 
GALT. We are unable to suggest any specific reliable criteria with acceptable interobserver agreement regarding lamina propria rimming. Also, the absence of continuity between the surface adenomatous component and submucosal glands does not completely exclude the possibility of PEM, as shown in our study (cases 2 and 7).

Nevertheless, unique cytologic features that are distinctive of GALT carcinoma have been suggested, including submucosal glands lined by a single layer of columnar cells with oncocytic cytoplasm and lack of goblet cells. Both of these features are reminiscent of special cell types in follicle-associated epithelium [2]. In our study, seven cases (63.6\%) showed goblet cells in the submucosa. No case showed submucosal glands lined by a single layer of oncocytic columnar cells. Hence, we insist that all 11 cases in this study have a submucosal tumor component more compatible with GALT-associated PEM.

Since their first description by Muto et al. [38], hemosiderin deposits in the submucosa, along with granulation tissue and fibroinflammatory reaction (so-called siderogenous desmoplasia), were considered characteristic histologic features of benign submucosal epithelium that are distinct from those of true invasive carcinoma $[11,12,37-45,57]$. The classic explanation is that repeated twisting or torsion of a long stalk of pedunculated polyp can cause epithelial misplacement into the submucosa to result in these histologic features. This is further supported by the preponderant occurrence in the sigmoid colon, where peristalsis is the most powerful $[12,38,41]$. However, in our study, no siderogenous desmoplasia indicating repeat tissue damage was identified. All eleven cases had the non-pedunculated macroscopic type and occurred both on the right-sided and left-sided of the colon. One possible explanation is that PEM in nonpedunculated colorectal neoplasms may be ascribed to a relative abundance of submucosal GALT. With respect to 'the microanatomical defect of muscularis mucosae' and 'the size of the submucosal GALT', Kealy [5] reported a positive correlation between maximum diameters of lymphoid nodules and gaps in the muscularis mucosae. In our study, the median value of the largest diameter of isolated submucosal GALT was $0.17 \mathrm{~cm}$ (range, 0.12 to $0.33 \mathrm{~cm}$ ). Increased number and size of submucosal lymphoid follicles can result in microanatomic defects in the muscularis propria, eventually causing GALT-associated PEM [11,12].

The defining feature of colorectal cancer, in contrast to premalignant neoplasm, is invasion of the muscularis mucosae into the submucosa [36,58-61]. This definition of colorectal adenocarcino$\mathrm{ma}$ is partly based on histologic knowledge that there are no lym- phatic vessels in normal colonic lamina propria. There is also a lack of clinicopathologic data showing intramucosal carcinoma with nodal metastasis, although 'the presence of lymphatic vessels in the colonic lamina propria of the pathologic states' and 'the presence of lymphovascular invasion in the colorectal intramucosal carcinoma' have been reported [62-65]. In certain circumstances, colorectal epithelial neoplasms can extend into the submucosa without histologic features of frank invasion.

Conventional cytologic features, such as anaplasia, loss of nuclear polarity, and nuclear-cytoplasmic ratio, have been used as criteria for the differential diagnosis of PEM versus true invasion, although this distinction is not widely accepted [57]. Adenomatous component showing high-grade dysplasia in the submucosa can mimic malignancy $[40,41]$. However, the grade of dysplasia in the submucosa itself may not match other pathologic parameters for the differential diagnosis of PEM. In our study, no statistical significance was identified in the relationship between "the grade of the dysplasia in the submucosa (high-grade dysplasia versus low-grade dysplasia)" and "the clinicopathologic features (including pathologic features for PEM, frank invasion, and GALT carcinoma)." Additionally, six cases showed similar grades of dysplasia between the submucosal component and surface component. The five other cases showed a less severe grade of dysplasia in the submucosa compared with that in the mucosa. No case showed high-grade dysplasia in the submucosa with low-grade dysplasia in the mucosa (Table 2, Fig. 1). Generally, invasive adenocarcinoma shows less differentiated tumor cells at the deepest part of invasion. However, adenoma with PEM shows a similar degree of differentiation between the surface component and the submucosal component $[37,38,43]$.

Our experience suggests that pathologists should be aware of the interpretation of GALT-associated submucosal extension of colorectal adenomatous neoplasms. This study is limited due to the small number of cases. Thus, further investigation with a larger number of cases and validation of the classification criteria of GALT-associated colorectal neoplasm is recommended.

\section{ORCID}

Yo Han Jeon: https://orcid.org/0000-0002-0353-7255

Ji Hyun Ahn: https://orcid.org/0000-0002-3312-788X

Hee Kyung Chang: https://orcid.org/0000-0002-4843-5316

\section{Author Contributions}

Conceptularization: HKC.

Data curation: HKC, YHJ, JHA. 
Formal Analysis: YHJ.

Investigation: YHJ, JHA, HKC.

Methodology: HKC.

Project administration: YHJ, JHA, HKC.

Resources: YHJ, JHA, HKC.

Software: YHJ.

Validation: HKC.

Visualization: YHJ.

Writing—original draft: $\mathrm{YHJ}$.

Writing—review \& editing: HKC, JHA.

\section{Conflicts of Interest}

The authors declare that they have no potential conflicts of interest.

\section{Funding}

No funding to declare.

\section{REFERENCES}

1. Neutra MR, Mantis NJ, Kraehenbuhl JP. Collaboration of epithelial cells with organized mucosal lymphoid tissues. Nat Immunol 2001; 2: 1004-9.

2. Rubio CA, Puppa G, de Petris G, Kis L, Schmidt PT. The third pathway of colorectal carcinogenesis. J Clin Pathol 2018; 71: 7-11.

3. Elmore SA. Enhanced histopathology of mucosa-associated lymphoid tissue. Toxicol Pathol 2006; 34: 687-96.

4. Langman JM, Rowland R. The number and distribution of lymphoid follicles in the human large intestine. J Anat 1986; 149: 189-94.

5. Kealy WF. Colonic lymphoid-glandular complex (microbursa): nature and morphology. J Clin Pathol 1976; 29: 241-4.

6. Sipos F, Muzes G. Isolated lymphoid follicles in colon: switch points between inflammation and colorectal cancer? World J Gastroenterol 2011; 17: 1666-73.

7. Nascimbeni R, Villanacci V, Mariani PP, et al. Aberrant crypt foci in the human colon: frequency and histologic patterns in patients with colorectal cancer or diverticular disease. Am J Surg Pathol 1999; 23: 1256-63.

8. Fu KI, Sano Y, Kato S, et al. Incidence and localization of lymphoid follicles in early colorectal neoplasms. World J Gastroenterol 2005; 11: 6863-6.

9. Shah N, Thakkar B, Shen E, et al. Lymphocytic follicles and aggregates are a determinant of mucosal damage and duration of diarrhea. Arch Pathol Lab Med 2013; 137: 83-9.

10. Rubio CA, Asmundsson J, Silva P, Illies C, Hartman J, Kis L. Lymphoid aggregates in Crohn's colitis and mucosal immunity. Vir- chows Arch 2013; 463: 637-42.

11. Shepherd NA, Griggs RK. Bowel cancer screening-generated diagnostic conundrum of the century: pseudoinvasion in sigmoid colonic polyps. Mod Pathol 2015; 28 Suppl 1: S88-94.

12. Lee HE, Wu TT, Chandan VS, Torbenson MS, Mounajjed T. Colonic adenomatous polyps involving submucosal lymphoglandular complexes: a diagnostic pitfall. Am J Surg Pathol 2018; 42: 1083-9.

13. McCarthy AJ, Chetty R. Gut-associated lymphoid tissue or socalled "dome" carcinoma of the colon: review. World J Gastrointest Oncol 2019; 11: 59-70.

14. Rubio CA, De Petris G, Puppa G. Gut-associated lymphoid tissue (GALT) carcinoma in ulcerative colitis. Anticancer Res 2018; 38: 919-21.

15. Zhou S, Ma Y, Chandrasoma P. Inverted lymphoglandular polyp in descending colon. Case Rep Pathol 2015; 2015: 646270.

16. Kannuna H, Rubio CA, Silverio PC, et al. DOME/GALT type adenocarcimoma of the colon: a case report, literature review and a unified phenotypic categorization. Diagn Pathol 2015; $10: 92$.

17. Yamada M, Sekine S, Matsuda T. Dome-type carcinoma of the colon masquerading a submucosal tumor. Clin Gastroenterol Hepatol 2013; 11: A30.

18. Rubio CA, Befrits R, Ericsson J. Carcinoma in gut-associated lymphoid tissue in ulcerative colitis: Case report and review of literature. World J Gastrointest Endosc 2013; 5: 293-6.

19. Yamada M, Sekine S, Matsuda T, et al. Dome-type carcinoma of the colon; a rare variant of adenocarcinoma resembling a submucosal tumor: a case report. BMC Gastroenterol 2012; 12: 21.

20. Puppa G, Molaro M. Dome-type: a distinctive variant of colonic adenocarcinoma. Case Rep Pathol 2012; 2012: 284064.

21. Coyne JD. Dome-type colorectal carcinoma: a case report and review of the literature. Colorectal Dis 2012; 14: e360-2.

22. Rubio CA, Lindh C, Björk J, Törnblom H, Befrits R. Protruding and non-protruding colon carcinomas originating in gut-associated lymphoid tissue. Anticancer Res 2010; 30: 3019-22.

23. Stewart CJ, Hillery S, Newman N, Platell C, Ryan G. Dome-type carcinoma of the colon. Histopathology 2008; 53: 231-4.

24. Asmussen L, Pachler J, Holck S. Colorectal carcinoma with domelike phenotype: an under-recognised subset of colorectal carcinoma? J Clin Pathol 2008; 61: 482-6.

25. Rubio CA, Talbot I. Lymphoid-associated neoplasia in herniated colonic mucosa. Histopathology 2002; 40: 577-9.

26. Jass JR, Constable L, Sutherland R, et al. Adenocarcinoma of colon differentiating as dome epithelium of gut-associated lymphoid tissue. Histopathology 2000; 36: 116-20.

27. Clouston AD, Clouston DR, Jass JR. Adenocarcinoma of colon differentiating as dome epithelium of gut-associated lymphoid tissue. 
Histopathology 2000; 37: 567.

28. De Petris G, Lev R, Quirk DM, Ferbend PR, Butmarc JR, ElenitobaJohnson K. Lymphoepithelioma-like carcinoma of the colon in a patient with hereditary nonpolyposis colorectal cancer. Arch Pathol Lab Med 1999; 123: 720-4.

29. Fritz A, Percy C, Jack A, Shanmugaratnam K, Sobin LH, Parkin MD. International Classification of Diseases for Oncology (ICD-O). 3rd ed. Geneva: World Health Organization, 2013.

30. Stintzing S, Tejpar S, Gibbs P, Thiebach L, Lenz HJ. Understanding the role of primary tumour localisation in colorectal cancer treatment and outcomes. Eur J Cancer 2017; 84: 69-80.

31. The Paris endoscopic classification of superficial neoplastic lesions: esophagus, stomach, and colon: November 30 to December 1, 2002. Gastrointest Endosc 2003; 58(6 Suppl): S3-43.

32. Vleugels JLA, Hazewinkel Y, Dekker E. Morphological classifications of gastrointestinal lesions. Best Pract Res Clin Gastroenterol 2017; 31: 359-67.

33. Endoscopic Classification Review Group. Update on the paris classification of superficial neoplastic lesions in the digestive tract. Endoscopy 2005; 37: 570-8.

34. Kudo S, Lambert R, Allen JI, et al. Nonpolypoid neoplastic lesions of the colorectal mucosa. Gastrointest Endosc 2008; 68(4 Suppl): S3-47.

35. Schlemper RJ, Hirata I, Dixon MF. The macroscopic classification of early neoplasia of the digestive tract. Endoscopy 2002; 34: 163-8.

36. Lokuhetty D, White VA, Watanabe R, Cree IA, Organizacion Mundial de la Salud; International Agency for Research on Cancer. WHO classification of tumours. Vol. 1. Digestive system tumours. 5th ed. Lyon: IARC Press, 2019.

37. Fenoglio-Preiser CM, Noffsinger AE, Stemmermann GN, Lantz PE, Isaacson PG. Gastrointestinal pathology: an atlas and text. 3rd ed. Philadelphia: Wolters Kluwer Health/Lippincott Williams \& Wilkins, 2008; 926-31.

38. Muto T, Bussey HJ, Morson BC. Pseudo-carcinomatous invasion in adenomatous polyps of the colon and rectum. J Clin Pathol 1973; 26: 25-31.

39. Dirschmid K, Kiesler J, Mathis G, Beller S, Stoss F, Schobel B. Epithelial misplacement after biopsy of colorectal adenomas. Am J Surg Pathol 1993; 17: 1262-5.

40. Yantiss RK, Bosenberg MW, Antonioli DA, Odze RD. Utility of MMP-1, p53, E-cadherin, and collagen IV immunohistochemical stains in the differential diagnosis of adenomas with misplaced epithelium versus adenomas with invasive adenocarcinoma. Am J Surg Pathol 2002; 26: 206-15.

41. Tanizawa T, Seki T, Nakano M, Kamiyama R. Pseudoinvasion of the colorectal polypoid tumors: serial section study of problematic cases. Pathol Int 2003; 53: 584-90.
42. Molavi D, Argani P. Distinguishing benign dissecting mucin (stromal mucin pools) from invasive mucinous carcinoma. Adv Anat Pathol 2008; 15: 1-17.

43. Loughrey MB, Shepherd NA. The pathology of bowel cancer screening. Histopathology 2015; 66: 66-77.

44. Panarelli NC, Somarathna T, Samowitz WS, et al. Diagnostic challenges caused by endoscopic biopsy of colonic polyps: a systematic evaluation of epithelial misplacement with review of problematic polyps from the bowel cancer screening program, United Kingdom. Am J Surg Pathol 2016; 40: 1075-83.

45. Ferreira da Silva MJ, Pinho R, Wen X, Tente D, Leite S, Carvalho J. Adenoma with pseudoinvasion: $s$ crucial differential diagnosis for invasive adenocarcinoma. Gastroenterol Hepatol 2017; 40: 96-8.

46. Chang HJ, Park CK, Kim WH, et al. A standardized pathology report for colorectal cancer. Korean J Pathol 2006; 40: 193-203.

47. Rubio CA. Ectopic colonic mucosa in ulcerative colitis and in Crohn's disease of the colon. Dis Colon Rectum 1984; 27: 182-6.

48. World Medical Association. World Medical Association Declaration of Helsinki: ethical principles for medical research involving human subjects. JAMA 2013; 310: 2191-4.

49. Nauss KM, Locniskar M, Pavlina T, Newberne PM. Morphology and distribution of 1,2-dimethylhydrazine dihydrochloride-induced colon tumors and their relationship to gut-associated lymphoid tissue in the rat. J Natl Cancer Inst 1984; 73: 915-24.

50. Carter JW, Lancaster HK, Hardman WE, Cameron IL. Distribution of intestine-associated lymphoid tissue, aberrant crypt foci, and tumors in the large bowel of 1,2-dimethylhydrazine-treated mice. Cancer Res 1994; 54: 4304-7.

51. Hardman WE, Cameron IL. Colonic crypts located over lymphoid nodules of 1,2-dimethylhydrazine-treated rats are hyperplastic and at high risk of forming adenocarcinomas. Carcinogenesis 1994; 15: 2353-61.

52. Rubio CA, Shetye J, Jaramillo E. Non-polypoid adenomas of the colon are associated with subjacent lymphoid nodules: an experimental study in rats. Scand J Gastroenterol 1999; 34: 504-8.

53. Rubio CA. The histogenesis of the third pathway of colonic carcinogenesis in rats. Anticancer Res 2017; 37: 1039-42.

54. Dukes C, Bussey HJ. The number of lymphoid follicles of the human large intestine. J Pathol Bacteriol 1926; 29: 111-6.

55. O'Leary AD, Sweeney EC. Lymphoglandular complexes of the colon: structure and distribution. Histopathology 1986; 10: 267-83.

56. Rubio CA, Schmidt PT. Gut-associated lymphoid tissue (GALT) carcinoma or dome carcinoma? Anticancer Res 2016; 36: 5385-7.

57. Greene FL. Epithelial misplacement in adenomatous polyps of the colon and rectum. Cancer 1974; 33: 206-17.

58. Fenoglio-Preiser CM, Lantz P, Listrom M, Noffsinger A, Riker F, 
Stemmermann G. Gastrointestinal pathology: an atlas and text. 2nd ed. Philadelphia: Lippincott-Raven, 1999.

59. Schlemper RJ, Itabashi M, Kato Y, et al. Differences in the diagnostic criteria used by Japanese and Western pathologists to diagnose colorectal carcinoma. Cancer 1998; 82: 60-9.

60. Risio M. The natural history of pT1 colorectal cancer. Front Oncol 2012; 2: 22 .

61. Quirke P, Risio M, Lambert R, von Karsa L, Vieth M. Quality assurance in pathology in colorectal cancer screening and diagnosis-European recommendations. Virchows Arch 2011; 458: 1-19.

62. Lewin MR, Fenton H, Burkart AL, Sheridan T, Abu-Alfa AK, Montgomery EA. Poorly differentiated colorectal carcinoma with invasion restricted to lamina propria (intramucosal carcinoma): a follow-up study of 15 cases. Am J Surg Pathol 2007; 31: 1882-6.

63. Kenney BC, Jain D. Identification of lymphatics within the colonic lamina propria in inflammation and neoplasia using the monoclonal antibody D2-40. Yale J Biol Med 2008; 81: 103-13.

64. Fenoglio CM, Kaye GI, Lane N. Distribution of human colonic lymphatics in normal, hyperplastic, and adenomatous tissue. Its relationship to metastasis from small carcinomas in pedunculated adenomas, with two case reports. Gastroenterology 1973; 64: 51-66.

65. Hashimoto $\mathrm{H}$, Horiuchi $\mathrm{H}$, Kurata A, et al. Intramucosal colorectal carcinoma with lymphovascular invasion: clinicopathological characteristics of nine cases. Histopathology 2019; 74: 1055-66. 